EPJ Web of Conferences 12, 01004 (2011)

DOI: $10.1051 /$ epjconf/20111201004

(C) Owned by the authors, published by EDP Sciences, 2011

\title{
Probabilistic and predictive performance-based approach for assessing reinforced concrete structures lifetime: The applet project
}

C. Cremona ${ }^{1, a}$, L. Adélaide ${ }^{2}$, Y. Berthaud ${ }^{3}$, V. Bouteiller ${ }^{2}$, V. L'Hostis ${ }^{4}$, S. Poyet ${ }^{4}$ and J.-M. Torrenti ${ }^{2}$

${ }^{1}$ Ministry of Ecology, Energy and Sustainable development, DRI, Tour Voltaire, 92055 La Défense, France

${ }^{2}$ University Paris-Est, LCPC, 58 Bd. Lefebvre, 75732 Paris Cedex, France

${ }^{3}$ UniverSud Paris, LMT, ENS Cachan, 61 avenue du Pr. Wilson, 94235 Cachan Cedex,

France

${ }^{4}$ CEA Saclay, DENIDANS/DPC/SCCME/LECBA, 91191 Gif-sur-Yvette Cedex, France

\begin{abstract}
Concrete deterioration results in different damage extents, from cracking to concrete spalling, from losses of reinforcement cross-sections to bond losses. A relevant prediction of this performance is the basis for a successful management of the concrete structures. Conversely, the large amount of uncertainties related to parameters and models require a specific analysis in order to provide relevant results. The APPLET project intends to develop a probabilistic and predictive performance-based approach by quantifying the various sources of variability (material and structure), studying the interaction between environmental aggressive agents and the concrete material, ensuring a transfer of the physical-chemical models at the material scale towards models at the structure level, including and understanding in a better manner the corrosion process, integrating interface models between reinforcement and concrete, proposing relevant numerical models, integrating know-how from monitoring or inspection. To provide answers, a consortium of 19 partners has been established and has promoted a research project funded by the French Research Science Agency (ANR). Started in May 2007, the project has ended in November 2010. This paper will resume the most significant advances targeted by this research project.
\end{abstract}

\section{INTRODUCTION}

One of the major challenges for new or existing concrete structures is the correct management of their service lifetime while maintaining their structural performance (durability, serviceability, structural safety). The stakeholders' needs and the development of European standards for a performance-based approach applied to civil engineering structures require to coordinate research forces from the different organisms working on these subjects. If these needs can differ from one structures' owner to another (in terms of service lifetime, risks...), due to the large variety of civil engineering concrete structures (buildings, bridges, historical structures, power plants...), the predictive capability of the structural performance remains a common denominator which has to be handled by a global and coherent approach. Satisfying this stake requires tools to ensure a correct mechanical behaviour of the structures in their environment along their lifecycle. These tools must be quantitative and predictive. In order to optimize the structures' lifecycle, the analysis of the structural performance must gain in precision. This objective requires improving the quality and the pertinence of the data coming from inspection, to adapt

ae-mail: christian.cremona@developpement-durable.gouv.fr

This is an Open Access article distributed under the terms of the Creative Commons Attribution-Noncommercial License 3.0, which permits unrestricted use, distribution, and reproduction in any noncommercial medium, provided the original work is properly cited. 


\section{EPJ Web of Conferences}

the structural models to the real conditions met by the structures, and to take into account the intrinsic and the statistical uncertainties about the material properties. Such methods and tools will allow a better assessment of the structural performance. An early decision, calibrated by on-site information, will economically improve the maintenance and repair actions. A probabilistic and predictive performancebased approach must call after robust models and methods. This robustness is particularly important for very long life structures (more than 100 years) or degraded ones.

Lifetime assessment for new or existing concrete structures is therefore an important challenge for the civil engineering field. According to the domain of applications, this assessment will necessitate different levels of knowledge for understanding the degradation phenomena. This understanding is directly related to the type of properties to be guaranteed or estimated. Understanding the ageing processes calls after multi-physics and multi-scale models. These processes are even more complex if the heterogeneity of the constitutive components has to be included. The interface and inter-reactivity problems of these components over a long term period constitute an essential part of these processes to study and to analyze. The corrosion of the steel bars in cementitious materials is such a problem and it constitutes one of the major causes of the degradation of concrete structures. Due to the large stock of concrete structures, maintenance decisions have to be efficient and pertinent: a correct assessment of the structural performance will condition largely the type and the extent of these management actions. They can be efficient only if pertinent predictive models are used along the different phases of the structural performance.

In the field of the modelling of concrete materials' behaviour, a lot of researches have been already made and before the beginning of the project, the APPLET consortium identified that it will be very difficult to innovate in that field. In the domain of durability and cracking modelling, several studies have also been made. Yet, several margins of progress remain in the experimental characterization and in the understanding of some physical phenomena. From a fundamental point of view, the theoretical difficulties related to the occurrence of a discontinuity in the concrete material have led to developments (theoretical and numerical) which allow only solving a small part of the problems. Above all, these approaches are not applicable for industrial uses and few advances have been really done on this point during the last fifteen years. For instance, the cracking phenomenon is rarely alone and has to be coupled with physical, chemical and thermal mechanisms. Civil engineers request robust, simple models based on strong physical bases: such is the ambition of the APPLET project.

\section{SCIENTIFIC TARGETS OF THE APPLET PROJECT}

Concrete deterioration results in different damage extents, from cracking to concrete spalling, from losses of reinforcement cross-sections to bond losses. A relevant prediction of this performance is the basis for a successful management of the concrete structures. The APPLET project considers these research and development requirements through the main objectives:

- to quantify the various sources of variability (material and structure) and to take them into account in probabilistic approaches;

- to include and to understand in a better manner the corrosion process, in particular by studying its influence on the steel behaviour;

- to integrate knowledge assets on the evolution of concrete and steel in order to include interface models between the two materials, and to propose relevant numerical models;

- to have robust predictive models to model the long term behaviour of degraded structural elements;

- to integrate know-how from monitoring or inspection.

For providing answers to these various objectives, the APPLET project has been divided into three working groups. A fourth working group has in charge the writing of guidelines or recommendations for stakeholders, laboratories and engineers based on the APPLET results. 


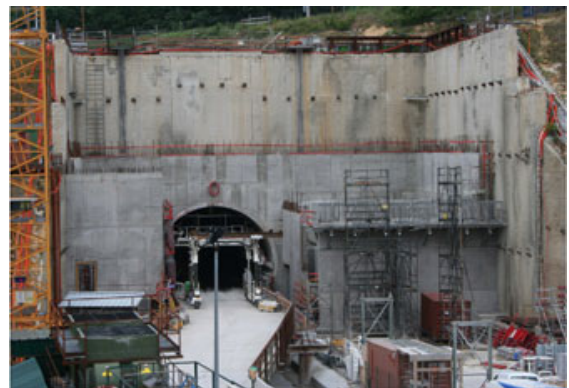

a) $\mathrm{A} 86$

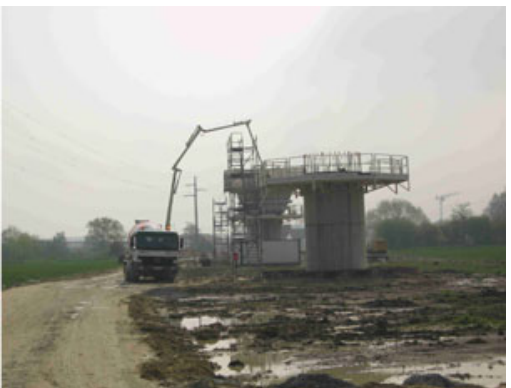

b) Compiègne viaduct

Figure 1. General view of the construction sites.

\section{CONCRETE/ENVIRONMENT INTERACTIONS}

The objective of working group $\mathrm{N}^{\circ} 1$ (WG1 - Concrete/environment interactions) is to take into consideration the variability of the material properties for a probabilistic performance-based approach of the service lifetime prediction of concrete structures. The WG1 studies are focused on the characterization of the variability from on-site production and on the consequences of this variability on transport processes in concrete (chlorides, water, carbon dioxide) and on chemical reactions (leaching, carbonation...). The analysis of these phenomena is strongly related to the other working groups. The time evolution of the depassivation and corrosion of steel bars indeed depends on the intrinsic evolution of the surrounding materials influenced by the coupled phenomena of chemical reactions and transport which modify the steel/concrete interface.

Two construction works have been identified to provide samples from construction works to the different research teams; the first one is the A86 tunnel and the second one the Compiègne viaduct. The concrete formulations are representative of classical industrial concrete: A86 tunnel slab (mean strength after 28 days equal to $50 \mathrm{MPa}$, CEM I + fly-ash - fig. 1(a)), Compiègne bridge pile (mean strength after 28 days equal to $40 \mathrm{MPa}$, CEM III - fig. 1(b)).

The concrete specimens are produced on site, maintained under water (standardized curing) and then delivered for tests. 40 deliveries of 15 sample sets per construction site (corresponding to 40 batches) have been sent to the research teams.

For the sorption tests (La Rochelle University), the 11 x $22 \mathrm{~cm}$ samples (A86 site) are maintained under water at $20^{\circ} \mathrm{C}, 24 \mathrm{~h}$ after their production. The samples are delivered in water tanks with the same water used for conserving the samples. In that case, the water is supposed to have the same ionisation force than the intersticial concrete water. After 3 months, the samples are cut into 3 disks with $11 \mathrm{~cm}$ diameter and $5 \pm 0.5 \mathrm{~mm}$ thickness. A $4 \mathrm{~mm}$ hole is drilled in each disk in order to hook them to a weighing machine. The samples are placed in water for 4 months (fig. 2).

The resistivity measurements (Bordeaux University) are usually performed on site to evaluate the probability of steel corrosion in reinforced concrete. They help to get information on factors influencing the corrosion process (humidity, presence of salts...) or to estimate bias factors on the electrochemical measurements (potential, polarization resistance). By their sensitivity to intrinsic concrete properties, the resistivity measurements form a promising technique for assessing the material durability. Within the APPLET project framework, the technique aims to provide information on the transfer properties. Based on a simplified version of the ChlorTest procedure [1], a cylindrical concrete specimen (in saturated condition) is placed between two metallic electrodes (fig. 3).

The accelerated lixiviation test with ammonium nitrate (CEA, ENS Cachan) has been introduced in order to characterize the degradation phenomena within an appropriate time duration [2, 3]. The objective is to correlate the physical variability of the materials with the displacement of the lixiviation 

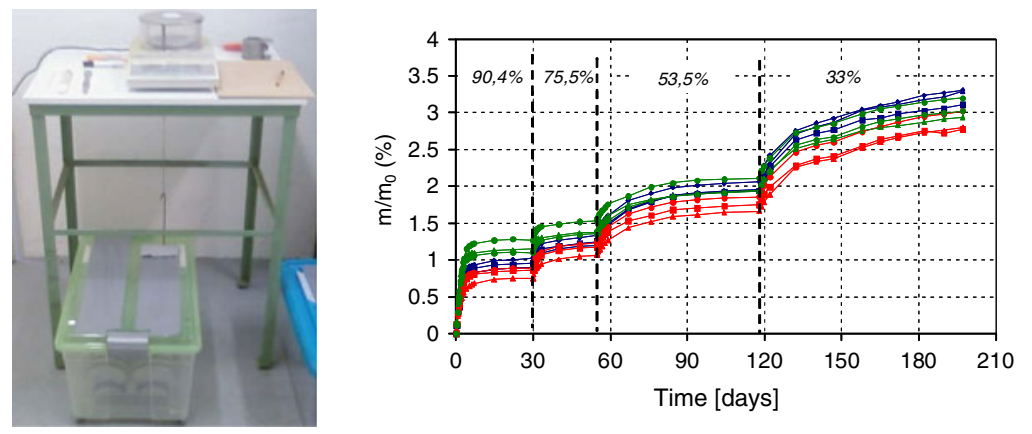

Figure 2. Example of soption test and results.
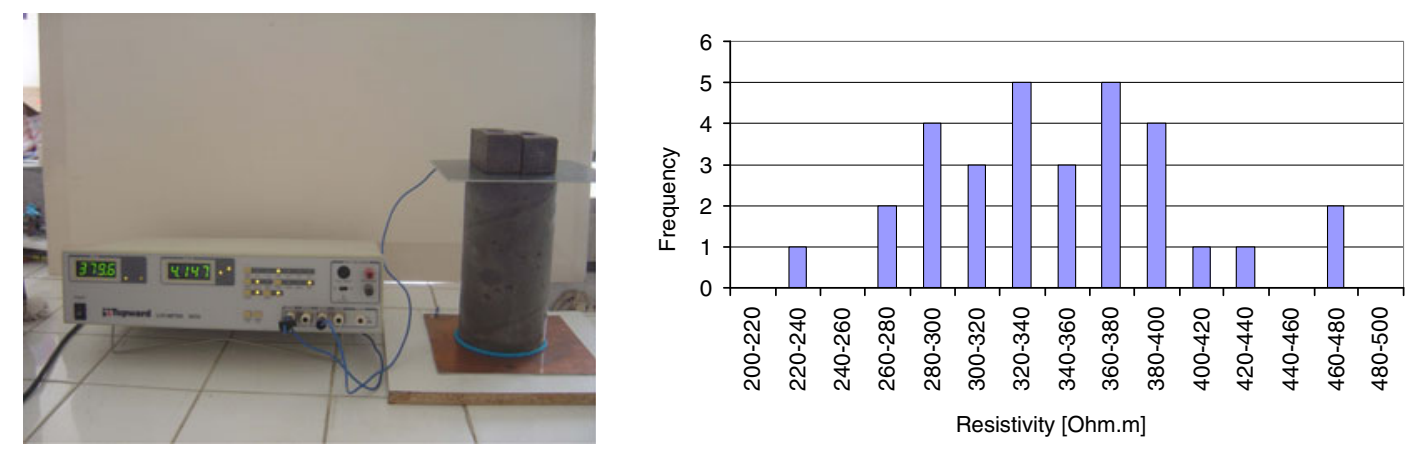

Figure 3. Example of resistivity test and results.

profile. The physical mechanisms introduced by the accelerated test are very close to those obtained with weak mineral water, but the test duration is shortened. Actually there is no reference procedure and the literature presents several test procedure applied to different types of materials, making impossible to identify the influence of the test procedures on the final results. Applying a probabilistic approach implies to assess the bias induced by the test procedure. This is the purpose of the APPLET project and a sensitivity analysis is performed in order to analyze the influence of different parameters of the procedure on the results. From the specimens, accelerated carbonation (CERIB, La Rochelle University) and chloride ingress (INSA Toulouse) $[4,5]$ tests are performed. For the carbonation tests, the AFPCAFREM (1997) procedure is applied but pre-conditioning treatment has been modified in order to obtain more homogeneous saturation profile over the sample depth. The accelerated chloride ingress test (fig. 4) is based on the NT Build 492 method [6]. Studies on hydric transfer are also performed by LCPC, Rochelle University and Polytech'Lille.

The construction of an experimental shell has for purpose to evaluate the spatial variability of the material properties. In connection with resistivity measurements - Bordeaux University), physical properties are evaluated and correlations are given on one hand between in-situ and specimen measurements and on the other hand between electrical and physical properties (fig. 5).

\section{MECHANICAL BEHAVIOUR OF DEGRADED CONCRETE STRUCTURES}

Working Group $\mathrm{N}^{\circ} 2$ (WG2 - Mechanical behaviour of degraded concrete structures) aims to provide efficient, robust, easy-to-use and realistic models for assessing the structural performance of concrete structures degraded by corrosion. From a mechanical point of view, the steel/concrete interface plays a 

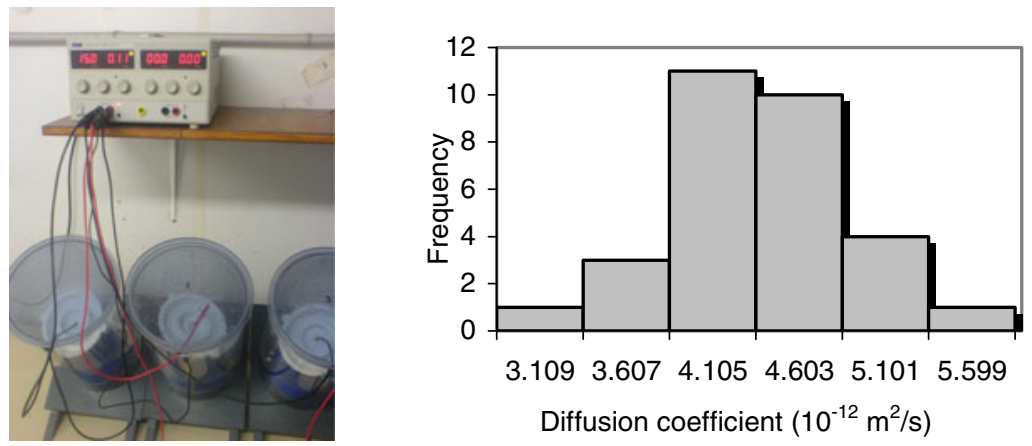

Figure 4. Example of NT Build 492 test and diffusion coefficient estimations.
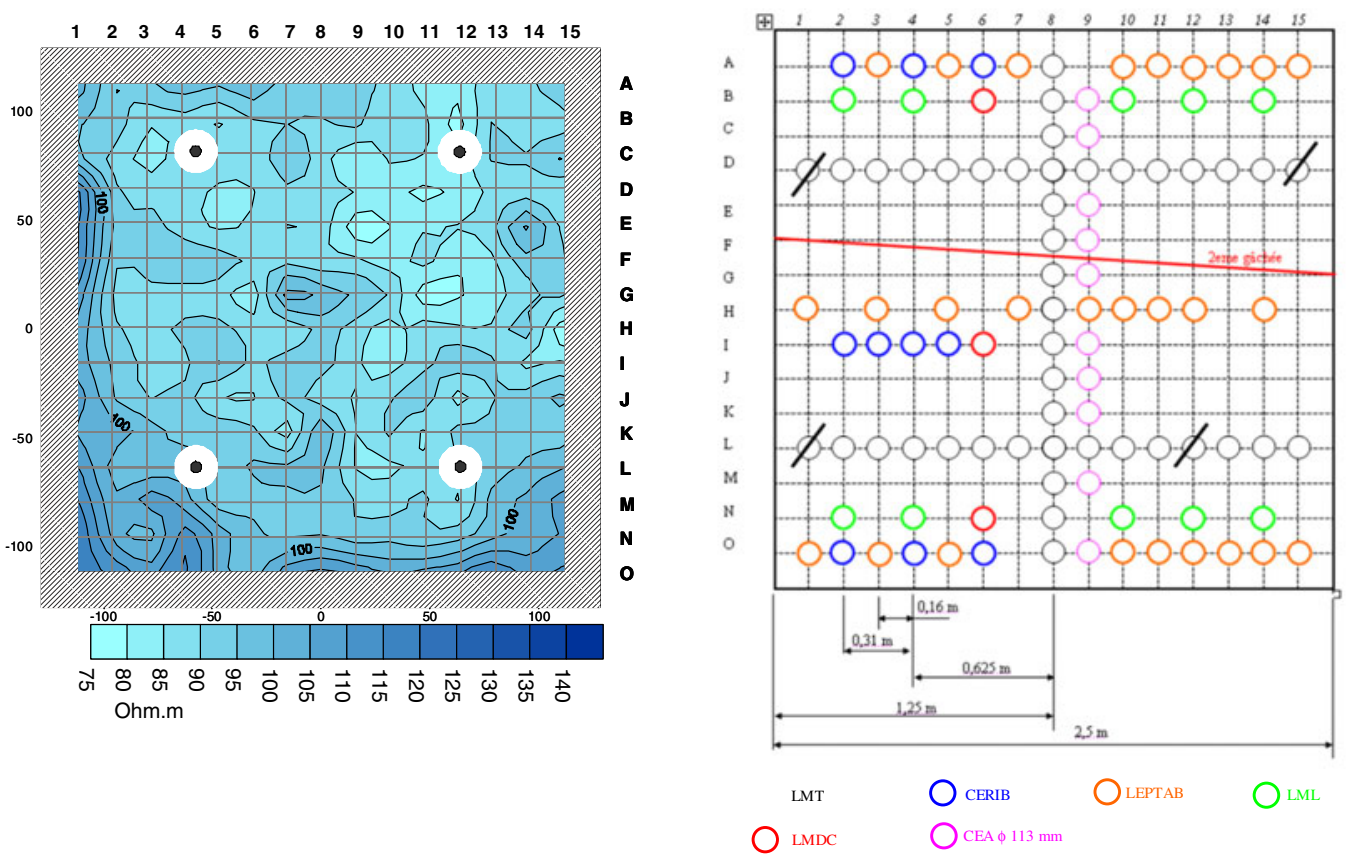

Figure 5. Experimental shell.

major role since it assured the transfer of forces between the two materials. The first task is to identify the influence of the corrosion on the steel behaviour. This experimental study is carried out by ENSCachan and INSA Toulouse; it consists in correlate the steel behaviour (loss of ductility and strength) with the level of corrosion. The second task is to analyse the effect of corrosion on the steel/concrete interface. Classically pull-out tests (fig. 6(a)) are performed for identifying the adherence between steel and concrete. This is a complex test procedure which does not ensure that uniform stresses around the steel bar. For this reason another approach was adopted (fig. 6(b)): the PIAF test. This one allows for the identification of the cohesion and of the fretting angle. This procedure is developed by ENS-Cachan. The PIAF test presents the advantage to reduce the lateral efforts that appear during pull-out tests and to measure the displacement field with an image processing software (fig. 7). It is therefore possible to observe the interface sliding during the test and to analyse the lateral confinement according to the type of bar (smooth non corroded, smooth corroded, ribbed). An interface model, based on joint elements, 


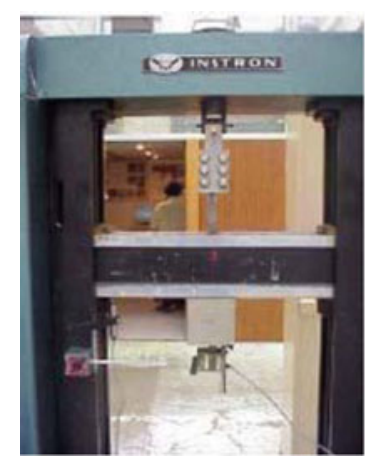

a)

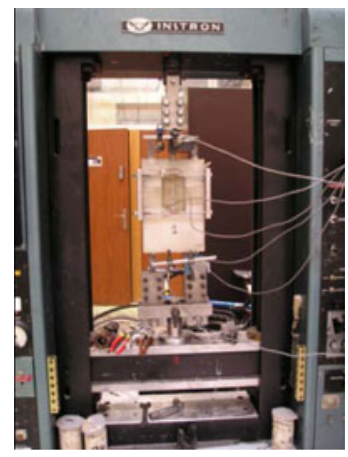

b)

Figure 6. Pull-out test (a) and PIAF test (b).

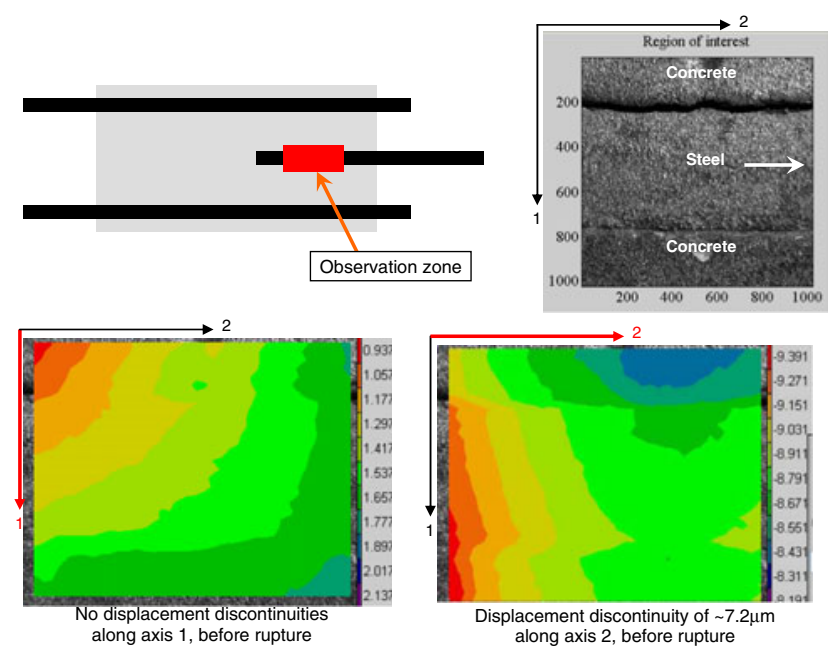

Figure 7. Image processing of the PIAF test.

has been developed following the Mohr-Coulomb criterion (concrete and steel are described by elastic models).

Based on the different models available in the literature, a third task was to develop an efficient and robust model for describing the mechanical concrete behaviour. For this purpose, LCPC has developed a model based on the principles of irreversible thermodynamic processes within the CAST3M FE software. It takes into account the opening and the closure of cracks, the sliding and the fretting of crack lips (fig. 8). This model has been coupled with an interface model which takes into account the corrosion influence.

A fourth task was to study the evolution of the bending stiffness versus corrosion. This is equivalent to consider the influence of the tended concrete between cracks relatively to the serviceability and ultimate limit states. Since this loss of stiffness is mainly due to the loss of adherence, the loss of load carrying capacity is related to the cross-section reduction in the rupture areas and the loss of ductility is related to the influence of the notches due to corrosion pitting. The experimental programme carried out by INSA Toulouse since 1984 is started again in the APPLET project. These very old beams have been placed in a saline fog during 6 years in a controlled environment (laboratory) and placed in real environmental conditions during 11 years. From the analysis done in the APPLET project, the evolution 

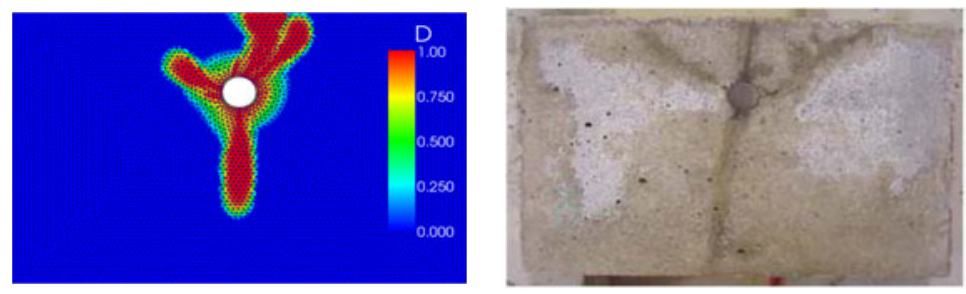

Figure 8. Example of cracking damage patterns.
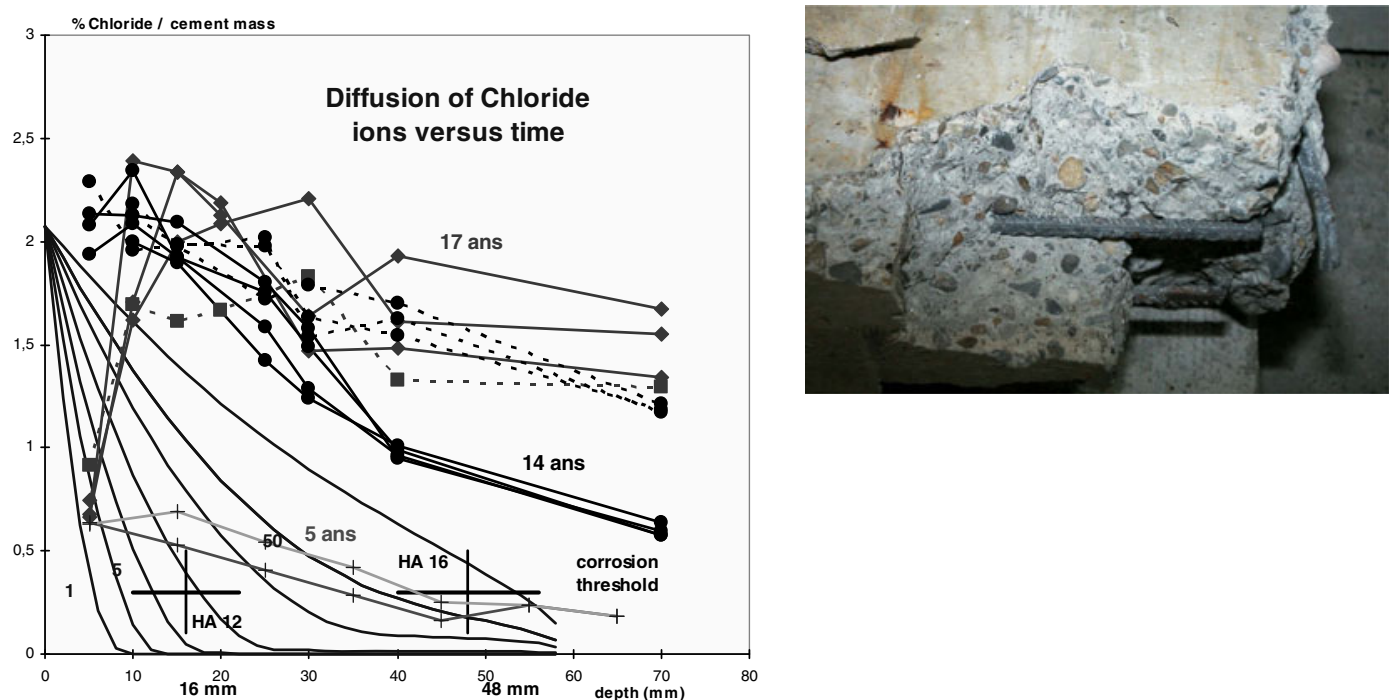

Figure 9. Corrosion initiation versus chloride content.

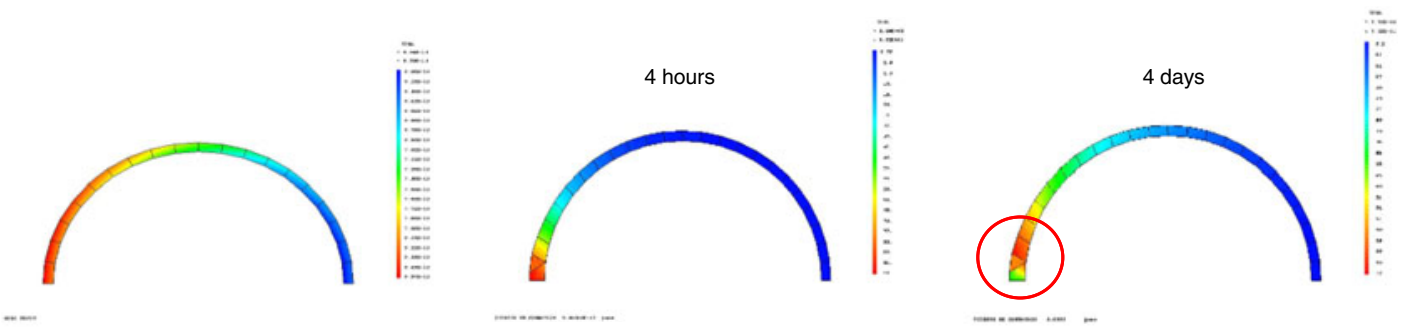

Figure 10. Reduction of the corrosion kinetics.

of the chloride ingress can be assessed, but the differences in the cracking initiation time can be also analysed. For instance, for the experimental profiles at 5, 14 and 17 years, the critical chloride contents are largely exceeded without any detection of corrosion (fig. 9).

Another task is to monitor pre-cracked concrete specimen in order to assess the corrosion kinetics. CEA has engaged experimental and analytical studies to get information on one hand on the type of corrosion products in the case of pre-cracked specimen, and on the other hand to model the presence of a crack on the corrosion kinetics (fig. 10). For this purpose, CEA has implemented in the CAST3M FE software the analytical Huet-Chitty model. 

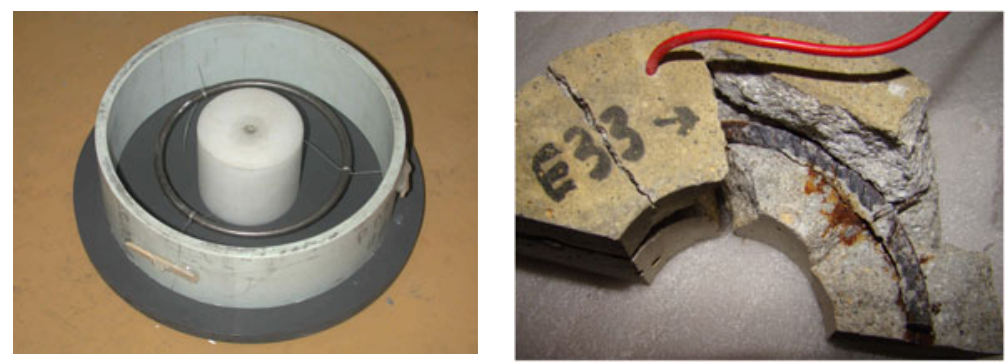

Figure 11. Experimental study of the auto-healing process.

At last, a final task is to check the development conditions of the corrosion process at the bottom of a crack. In particular, the self-healing of the first corrosion products have been studied (INSA Toulouse). With the help of a specific device (fig. 11), the objective is to create mechanical cracking (from 0 to $60 \mu \mathrm{m}$, from $60 \mu \mathrm{m}$ to $300 \mu \mathrm{m}$ and from $300 \mu \mathrm{m}$ to $1 \mathrm{~mm}$ ). From the crack size and the exposure period, the healing capability will be evaluated according to the crack threshold leading to a corrosion initiation, the crack threshold related to the corrosion ending, and the crack threshold facilitating a corrosion progression.

\section{ELECTROCHEMICAL DIAGNOSIS OF DEGRADED STRUCTURES}

A previous research project [7] has been the starting point of the Working Group $\mathrm{N}^{\circ}$ 3’s studies (WG3 Electrochemical diagnosis of degraded structures). This later project had shown a large dispersion of the experimental results of the corrosion intensity depending on the type of measurement system used. Such results were considered as worrying if rehabilitation or repair decisions have to be taken accordingly. Furthermore it is necessary to be careful when using the RILEM threshold values (polarization resistance for instance) because they are also depending on the system. For this reason, the APPLET project and its WG3 endorsed the responsibility to provide more critical answers regarding the efficiency and the reliability of the different measurement systems on a large experimental campaign.

The WG3 experimental programme consists in studying the influence of the parameters from different measurement systems and of environmental conditions (temperature and relative humidity). For this purpose, three types of specimens were elaborated: slab, small slab and small-scale samples (fig. 12). The small-scale samples (fig. 12(a)) have been designed to study the influence of the temperature and relative humidity. The small slabs are dedicated to the study of the parameters (polarized area). The slabs are useful for comparing measurements from small slabs and in situ specimens. The same cement (as used by the other WGs) has been used (Holcim CEM I 52.5 N CE CP2 NF). Smooth bars are used and they are protected from corrosion outside the studied section. The specimens are placed in different conditions. For the small slabs, the following conditions have been applied: reference (healthy concrete $-\mathrm{T}$ ), chlorides mixed during fabrication $(\mathrm{G})$, chlorides penetrated by immersion/drying process (I), carbonation (C).

The small slabs (fig. 12(b)) are maintained at $20{ }^{\circ} \mathrm{C} \pm 2{ }^{\circ} \mathrm{C}$ with $60 \% \pm 10 \%$ relative humidity. For specimens $(\mathrm{G}), \mathrm{NaCl}$ is added during mixing (5\% in weight of the cement weight). The small slabs (I) are subject to immersion/drying cycles (salted water $-35 \mathrm{~g} / \mathrm{l}$ ), during 4 immersion days followed by 3 drying days. The chloride content to get is $0.4 \%$ relatively to the cement weight. Cores are taken in order to monitor the overall process. The small slabs (C) are placed in a climatic chamber at $45^{\circ} \mathrm{C}$ with $65 \%$ RH followed by a carbonation phase. The objective is to get a $5 \mathrm{~cm}$ carbonation front (4-5 months). The same processes have been considered for the slabs (1 slab per condition - fig. 12(c)). The small samples are cut from a set of small slabs and are therefore concerned by the same experimental conditions. The 


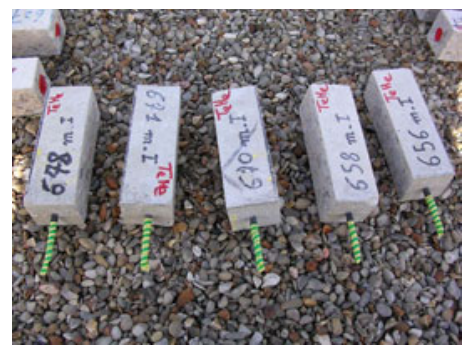

a) 160 small samples $(15 \times 15 \times 5 \mathrm{~cm})$

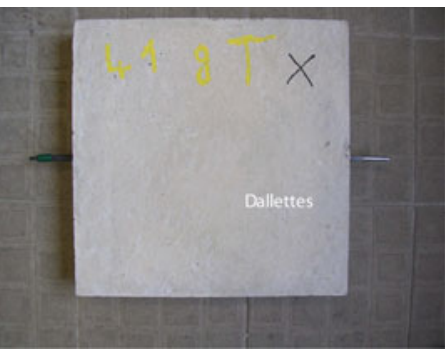

b) 56 small slabs $(30 \times 30 \times 5 \mathrm{~cm})$

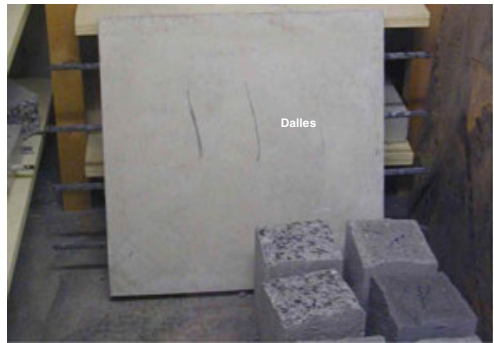

c) 4 slabs $(60 \times 60 \times 7 \mathrm{~cm})$

Figure 12. Small-samples (a), small slabs (b) and slabs (c).

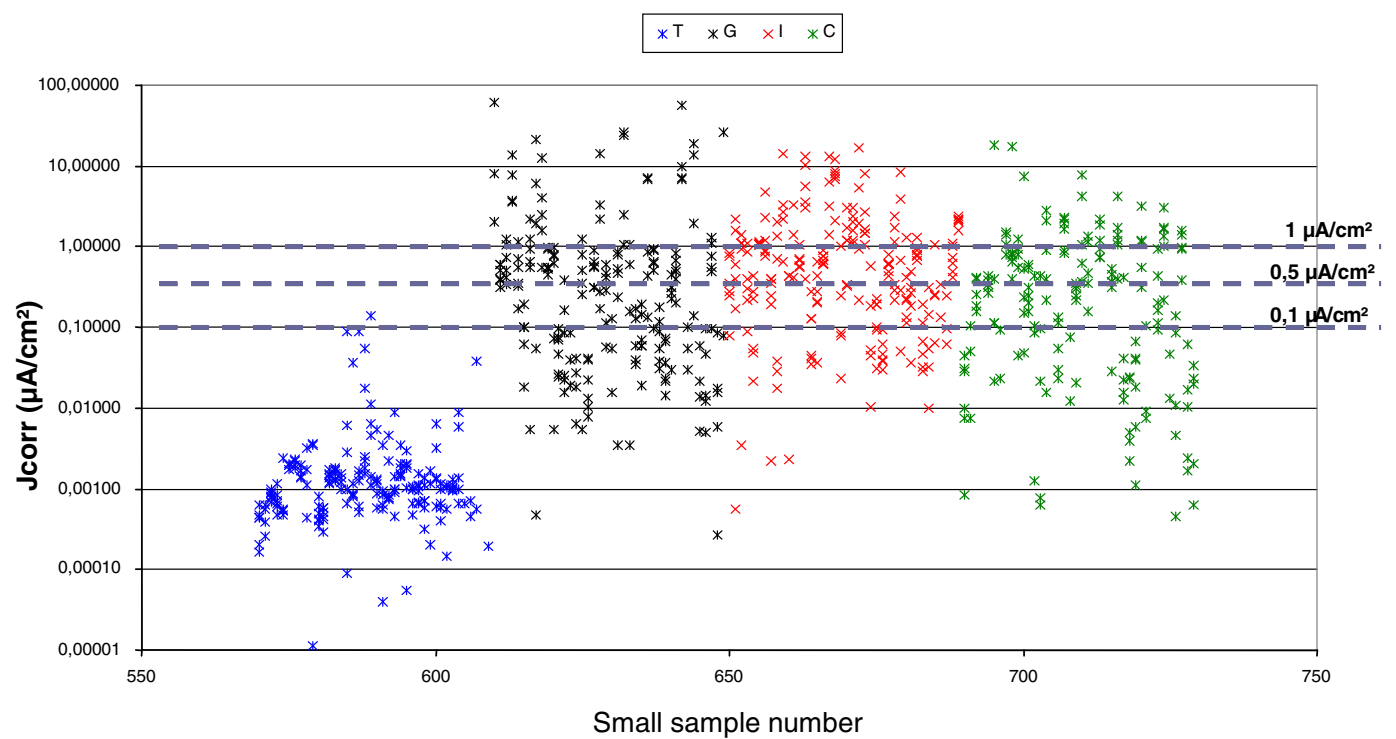

Figure 13. Corrosion intensity on small samples.

analysis of the different specimens is still under progress but it comes out already several interesting results (fig. 13).

In particular, for the small samples, the different results show that the corrosion depends on the temperature and humidity, but also on the condition (, $\mathrm{G}$ or $\mathrm{C}$ ). The free potential is not sufficient to describe the corrosion process, the corrosion intensity and the resistivity are also necessary. It is important to be careful regarding the corrosion kinetics which can be extrapolated from experimental results.

The experimental programme is completed by numerical analyses (INSA Toulouse) with the COMSOL Multiphysics@ (fig. 14) and by an experimental programme on existing structures (fig. 15).

\section{CONCLUSIONS}

For the management of existing structures or for the design of new ones, one of the most important challenges is the control of their lifetime, while maintaining an optimal allowable response to the 


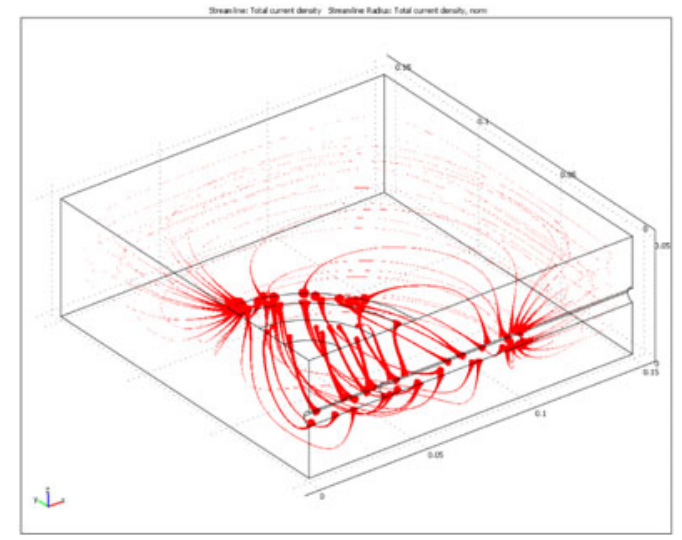

Figure 14. Current lines of a simulated small-slab.
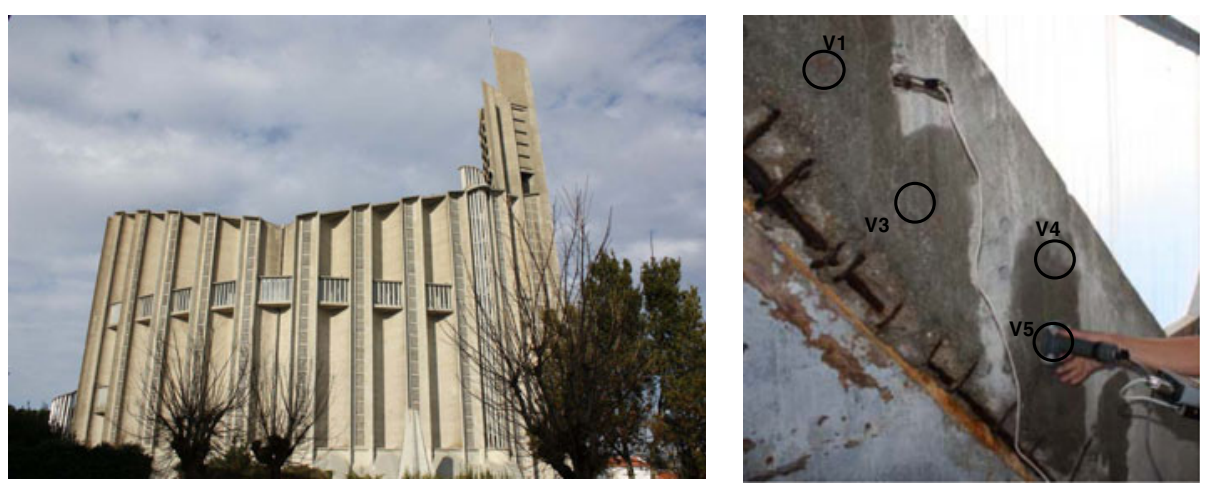

Figure 15. Royan cathedral and intensity corrosion measurement.

performance requirements (durability, serviceability, structural safety). The needs of the structure owners, and the professional world in general, the developments of European standards based on a performance-based approach imply to join together the efforts of various institutions working on these subjects. Among the structure stocks, concrete structures constitute the largest ones in number and in quality, since it covers pipes, pylons, silos, buildings, monuments, or bridges... The maintenance of those ageing structures is thus a major economical challenge at the time when their average age will force to make important choices concerning their maintenance, their lifetime extension or their replacement. Easy-to-use and economical, concrete is the main component of the construction sector and accounts for $53 \%$ in volume of the demolition wastes, and for $8 \%$ of the world $\mathrm{CO} 2$ emission. In this context, durability, performance requirement, exposure to environment, residual lifetime form part of the challenges participating to the development of durable constructions. The results from the APPLET project provide data and information which will be useful for further studies. The large experimental campaigns (WG1 and WG3) will constitute a tremendous basis for researchers. The numerical models which have been developed and implemented in various FE programs will constitute a strong platform for further developments. This paper cannot cover all the work done and all the results obtained during the past 4 years. A special issue of the European Journal of Civil and Environmental Engineering will be dedicated to the major results of the APPLET project [8]. 
AMP 2010

The investigations and results reported herein are supported by the National Research Agency (France) under the APPLET research program (grant ANR-06-RGCU-001-01). The partners of the project are Vinci construction France, CERIB, Oxand, CEA, INSA Toulouse, ENS - Cachan, LCPC, LERM, LRMH, Polytech'Lille, Bordeaux University, La Rochelle University, EDF/SEPTEN, IRSN, IETCC (Spain), CSTC (Belgium), LREP, LRPC Lille, Syrokko.

\section{References}

[1] ChlorTest EU project, Models for chloride ingress into concrete: a critical analysis, WP 4, Task 4.1. (2004).

[2] C. Carde, R. Francois R., J.M. Torrenti J.M., Leaching of both calcium hydroxyde and $C-S-H$ from cement paste: modeling the mechanical behavior, Cem. Concr. Res., 26, 1257-1268 (1996).

[3] U. Schneider, S.W. Chen, Behavior of high-performance concrete under ammonium nitrate solution and sustained load, ACI Materials Journal, 96, 1, 47-51 (1999).

[4] AFPC-AFREM, Durabilité des bétons - Méthodes recommandées pour la mesure des grandeurs associées à la durabilité, Compte-rendu des journées techniques AFPC-AFREM, 11-12 décembre 1997, Toulouse (1997).

[5] GranDuBé, Grandeurs associées à la Durabilité des Bétons, (Presses de l'Ecole Nationales des Ponts \& Chaussées, 2007).

[6] NordTest, Concrete, hardened: accelerated chloride penetration, Nordic standard test method NT Build 443 (1995).

[7] V. L'Hostis (dir.), Benchmark des poutres de la Rance - Diagnostic et modélisation mécanique des poutres en béton armé et précontraint atteintes par la corrosion des aciers, Revue Européenne de Génie Civil, Vol. 1-2 (2007)

[8] C. Cremona (dir.), Probabilisty-based approach for assessing the performance of concrete structures, European Journal of Environmental and Civil Engineering, to be published (2012). 